\title{
Research on the Integrated Teaching of Welding Specialty in Higher Vocational Schools
}

\author{
Zhi-ling Wang \\ Jiangsu Province Xuzhou Technician Institute \\ Xuzhou 221151, China \\ 379713268@qq.com
}

\begin{abstract}
The integrated teaching has become a popular word in the vocational education. With many years of teaching practice, the author has explored and accumulated some experience. The author proposes that the reform of the welding specialty should be integrated, specialized and combined with professional skills. The integrated teaching reform of welding specialty should be carried out from the aspects of curriculum standard, teaching material design, teacher qualification, teaching process and teaching environment. Through many years of teaching practice and comparison, we have adopted the basic idea of "integration of science and reality" to implement the teaching mode of "taking learning as the center", thereby realizing the docking of curriculum content and professional standards, the docking of teaching process and production process, and the docking of academic certificate and professional qualification certificate. Practice has proved that our welding professional students' competitiveness in the job search process has been greatly enhanced.
\end{abstract}

Keywords-Higher vocational schools; Educational activity; Integrated teaching

\section{INTRODUCTION}

With the increasing demand for skilled talents in China, the vigorously developing vocational and technical education has become a common topic for the intellectuals [1]. Most of the higher vocational and technical schools are aware of the disadvantages of the subject curriculum system, they are actively reforming at the same time. The integrated teaching has become a popular word in the vocational education. With many years of teaching practice, the author has explored and accumulated some experience [2]. The author proposes that the integration of the reform of the welding specialty should be integrated, specialized and integrated with professional skills. The integrated teaching reform of welding specialty should be carried out from the aspects of curriculum standard, teaching material design, teacher qualification, teaching process and teaching environment.

\section{THE INTEGRATED CURRICULUM STANDARDS}

The teaching plan is the basis for the school to organize the teaching [3]. Meanwhile, the teaching plan is also the guiding document for the formulation of the syllabus and the implementation of teaching. To ensure the implementation of "integration" teaching, we must formulate the "integration" teaching plan.

The characteristic of the integrated teaching plan is to combine the branch of the branch of the traditional teaching plan with the branch of the division of the branch to study the theory and practice, and combine the theoretical knowledge with the operational skills, through the study, in the study, and in the middle school, to greatly improve the students' interest in learning. First of all, the teaching plan is based on the national welding professional standards, focusing on students, with "necessary" and "enough"[4]. When we make a plan, we can fully investigate the production and technological development needs of the enterprise, and take into account the specific actual situation of the school. According to the technical requirements of the "middle, high and technician" welders, we have formulated different levels of teaching goals and professional abilities. We make a comprehensive analysis of the related knowledge and skills related to drawing courses, electrical basic courses, metal materials and heat treatment courses, welding principles, welding methods, welding skills training and so on, and divide the courses into several units. Each unit is divided into several modules according to the different knowledge points. Then we adopt different teaching and evaluation methods according to different subjects, and formulate specific teaching objectives and skills requirements for each topic or module. For example, according to the typical welding method, we divide the teaching process into eight parts: welding electrode arc welding, $\mathrm{CO} 2$ gas protection welding, manual argon arc welding, arc welding improvement training, special method welding, typical material welding, typical structure beam and column welding, welding production application and so on.

We guarantee each teaching unit to include Theoretical knowledge of different depths and breadth. According to the national welding professional standards and the needs of enterprise organization production and technology development, we divide the teaching objectives and skills of the theoretical knowledge and operation skills involved in each unit: the three units before the intermediate workers are 
completed, the top six units completed by the senior workers, and the technicians completing the eight units in the whole department.

The integrated teaching syllabus should carry out the integrated teaching concept, which is not only the guiding document of the teaching link, but also the basis for the compilation of teaching cases and the implementation of teaching and evaluation. On the basis of the national professional standards, we study and analyze the professional ability of the enterprise on the basis of the national professional standards. The teaching contents, class hours, teaching objectives and skills requirements of each topic were determined in the integrated syllabus. At the same time, it also determines the teaching requirements and skills objectives of different qualification talents.

In the compilation of the integrated syllabus, we also take full account of the application and development of new welding technology, new technology, new equipment and new materials. At the same time, the integrated teaching process also requires us to organize students to visit and Study on a regular basis, enhance students' perceptual knowledge, improve their interest in learning theory knowledge, and change passive learning into active needs.

\section{INTEGRATION AND INTEGRATION OF TEACHING MATERIAL CONTENT STRUCTURE.}

Integrated teaching materials are the basis for completing the integrated teaching requirements and skills objectives. We write integrated teaching materials according to the principles of integrated teaching plan, syllabus and professional standards, in accordance with the principles of science, rationality, practicality, pertinence and effectiveness. The compilation of teaching materials follows the cognitive law of "from practice to theory, from theory to practice".

The integrated teaching mode requires that we can not simply pursue the integrity of the subject. We need to design a new type of teaching material. The new teaching material should be able to combine the teaching requirements and the skills goals fully, and combine the basic theory with the professional skills together. According to the training target, ability factor and post demand of the welding specialty, we select the basic theory, the content of professional theory knowledge and the practical education link, and integrate into an organic whole. We synthesized the above requirements and worked out a comprehensive practical curriculum system with the aim of cultivating comprehensive ability as the main body and highlighting skills and job requirements. Our teaching and research leader took the lead in organizing the backbone teachers to compile integrated teaching materials. At the time of writing, we always adhere to the reform of the comprehensive and systematic curriculum system of the traditional teaching materials and the integration of the contents of the curriculum. Our integrated teaching materials adhere to the principle of operating skills as the backbone and the theoretical knowledge for the operational skills.

In the welding module of the container, we take the pre welding preparation and welding assembly process as the guide, through the related knowledge of riveting plate gold, such as the knowledge of layout, expansion, blanking, deformation and welding inspection, such as the knowledge of ray flaw detection, ultrasonic flaw detection and so on. Then, on the basis of the above principles and theoretical studies, we explain the related problems and concepts more carefully, control and guide the practice of welding through the theoretical knowledge taught, and finally achieve the goal of the skills. Through the above teaching design process, our students not only master operational skills, but also quickly understand the relevant welding theory and become knowledge-based skilled personnel.

\section{THE "DOUBLE QUALIFIED" TEACHING TEAM IS THE KEY TO THE IMPLEMENTATION OF INTEGRATED TEACHING.}

The vocational school teachers, first of all, should love the career education, should update the concept of vocational education, should be rich in dedication and innovative consciousness, should have good ideological and moral cultivation and high cultural quality, the above requirements are the basic qualities that teachers should have. The integrated teachers should have rich theoretical knowledge and excellent operational skills, and have the ability to use various teaching modes and professional teaching methods skillfully. "Double professionalism" teachers can undertake this important task.

The "double qualified" teaching staff is the key to the implementation of integrated teaching. The "double teacher" teacher means that the teaching staff not only understand the professional theory knowledge, obtain professional qualifications of vocational education series, but also have excellent operational skills, and obtain professional qualifications corresponding to the post ability (at least the professional qualification of senior technicians), which can teach both professional theory knowledge and guide production practice. This is undoubtedly a challenge to our vocational education teachers, and it is also an opportunity for vocational education teachers. We should seize this opportunity, study hard and keep getting into it and become a real "double teacher". Specialization" is the "specialized teacher" of welding specialties, which is different from other specialties. It is the guarantee for students to master the welding skills better. In Europe, welding professional teaching teachers are divided into electrode arc welding teachers, carbon dioxide welding teachers, argon arc welding teachers, etc.

The professionalization and integration of this kind of welding teacher is not contradictory. On the contrary, the specialized welding teacher has a more exquisite technique for some welding method on the basis of integration and integration. It is a "double teacher professionalization" teacher. In the course of instruction and training, the welding method can be better and more complete to some kind of welding method. Instruct and teach students face to face, so that students can better master some welding operation skills and professional theoretical knowledge. 


\section{THE TEACHING PROCESS EMBODIES THE ORGANIC UNITY OF INTEGRATION AND SPECIALIZATION.}

The theoretical structure of the theoretical courses in the former and the practical courses led to the poor learning effect of the two courses. When learning theories, students often feel that theoretical knowledge is empty, abstract and difficult to understand because of their lack of practical experience.

The integration of teaching process is the way to ensure the realization of teaching requirements and skills goals. The integration of the teaching process is guided by the principle of combining theory with practice, with the operation skills as the backbone, and a series of relevant theoretical knowledge through the practical operation of the students, to stimulate and guide the students' study theory. Since our students have some practical experience in practice, we can understand the theoretical knowledge deeply and make the theoretical knowledge give full play to the function of guiding practice. The learning process of "practice, understanding, practice and recognition" enables students to "know what they are" so as to cultivate students' ability to solve problems creatively.

The integrated teaching process requires us to adopt teaching methods such as project teaching, module teaching and interactive teaching. Through the above teaching methods, we can make our students not only master practical skills, but also quickly learn professional theories.

The curriculum of integrated vocational education does not ignore the study of theoretical knowledge, but emphasizes that students should learn the relevant theoretical knowledge in a more reasonable and effective way.

Because of the integration of teaching process, learning objects are not abstract, easy to understand and grasp, and they can get a sense of achievement and stimulate students' interest in learning. With the continuous deepening of learning and the continuous improvement of practical skills, students continue to build their own knowledge structure, and at the same time, there will be a need for further study of theoretical knowledge and desire. For example, in the welding competition of the senior welder class students, the students who have won the name have greatly enhanced the knowledge of welding theory.

Interactive teaching and skills competition can not only check the effect of teaching, but also stimulate learning enthusiasm. Students who do not get the rank will feel a sense of urgency. They will also ask questions to teachers. In this teaching process, backward students will make great efforts, because no one wants to lag behind.

The integrated teaching process should have distinct and comprehensive characteristics, and should always focus on the subject of the professional skills of the training object. At the same time, according to the requirements of professional teaching and skill, the requirements for the diversity, type and particularity of the enterprise production position should be considered. Therefore, in the course of teaching, it is necessary to adhere to the technology. It can be the key and the principle of practicality. For example, carbon dioxide gas shielded welding unit, his backbone or skill goal is to master the basic skills of carbon dioxide welding, but the knowledge and theory to be used to unfold it includes a series of disciplines such as welding technology, metal materials science, electrotechnics, physical chemistry and so on. It is necessary to combine reasonably and organically in order to meet the needs of career goals.

This requires teachers with both professional knowledge and professional skills to teach. In the course of teaching, we can argue for the application and development of new technology, new technology, new equipment and new materials. It is possible to organize students to visit and learn from the enterprises, consult the workers under the guidance of the teachers, and understand the skills required for the welding posts in person. For advanced welding equipment, such as submerged arc welding and stirred friction welding, we can use digital camera to record and design multimedia courseware, enhance students' perceptual knowledge, improve students' interest in learning theory knowledge, and change passive learning into active needs. The integrated, specialized and integrated teaching process has gradually become the mainstream method of higher vocational schools.

\section{BUILDING AN INTEGRATED TEACHING SITE}

The integrated teaching site is an important material guarantee for implementing integrated courses. It can not only satisfy theoretical teaching but also satisfy practical teaching. So the teaching site is both a classroom and a workshop, as well as a laboratory. Integrated classrooms should have blackboard, desk, electric education, and multimedia equipment; integrated workshop must have welding equipment, cutting equipment, ventilation equipment, worktable, related tool protector and storehouse, etc. the integrated laboratory should have experimental instruments corresponding to the experiment.

The construction of integrated teaching site integrates many functions of classroom, workshop and experiment, so that the teaching process can meet the needs of reform.

\section{CONCLUSION}

The integrated teaching of welding specialties is based on the goal of professional posts, guided by the skill operation, and through the comprehensive teaching process of "double professional" teachers, and training the system engineering of high skilled personnel to meet the needs of social enterprises. The integration of teaching reform requires us to make efforts in terms of curriculum standards, teaching materials, teaching staff, teaching process and teaching venues. The teachers, for the brilliance of vocational education, contribute our ingenuity to the strong and unselfish of our mother land.

\section{REFERENCES}

[1] Based on the THSCCG-1 type training platform, the teaching of integration of theory and practice is explored. [J]. Ma Juan. Intelligence. 2017 (09).

[2] Secondary vocational school computer professional integration of theory and practice teaching [J]. seal. Guangxi education. 2017 (10).

[3] The exploration of polymer materials processing equipment and mold "integration of science and reality" course [J]. Wang Chao. Technology and education. 2016 (04).

[4] Explore the teaching mode of "integration of theory and practice" in Higher Vocational Colleges [J]. Wang Xinyuan. China training. 2016 (20). 